\title{
TANATOGRAFIAS E DECOMPOSIÇÕES BIOGRÁFICAS: DISCURSO DA MORTE NA LITERATURA
}

\section{TANATOGRAPHIES AND BIOGRAPHICS DECOMPOSITIONS: DISCOURSE OF DEATH ON LITERATURE}

\author{
Augusto Rodrigues da Silva Junior
}

RESUMO: De uma perspectiva bakhtiniana, pretende-se mapear diferentes questões suscitadas pela aproximação entre literatura e morte. Constrói-se, assim, uma tanatografia do personagem que volta para existir, recordação de si para o outro e/ou na memória coletiva: Odisseia, Sátira Menipeia, Hamlet, Bobók e Memórias póstumas de Brás Cubas etc. Analisa-se uma imagem do cânone ocidental na perspectiva comparativista dialógica e, com isto, traça-se uma arquitetônica literária que extrapola os campos da citação e permite estudar variadas realizações discursivas da morte.

PALAVRAS-CHAVE: tanatografia, literatura comparada, morte, dialogismo.

ABSTRACT:This paper aims to map different issues raised by the approachement between literature and death from a Bakhtinian perspective. It forms a tanatography of the character who comes back from the dead, recalling himself to another and/or in collective memory: the Odyssey, Menipean Satire, Hamlet, Bobok and Posthumous Memoirs of Bras Cubas. It analyzes an image of Occidental canon in a dialogical comparativist perspective and thus draw a literary architecture that goes beyond the fields of quotation and that allows us to study various discursive achievements of death. KEYWORDS: tanathography, compared literature, death, dialogism.

\footnotetext{
* Universidade de Brasília (UnB), Brasília/DF. Professor Adjunto de Literatura Brasileira. Doutor em Literatura Comparada pela Universidade Federal Fluminense (UFF). Email: augustorodriguesdr@gmail.com.
} 

- O inferno dos vivos não é algo que será; se existe é aquele que já está aqui, o inferno no qual vivemos todos os dias, que formamos estando juntos. Existem duas maneiras de não sofrer. A primeira é fácil para a maioria das pessoas: aceitar o inferno e tornar-se parte deste até o ponto de deixar de percebê-lo. A segunda é arriscada e exige atenção contínua: tentar saber reconhecer quem e o que, no meio do inferno não é inferno, e preservá-lo, e abrir espaço (Calvino, Cidades Invisíveis, p. 150).

Pensa por ex. mais na morte, - e seria estranho em verdade que não tivesse de conhecer por esse facto novas representações, novos âmbitos da linguagem (Wittgenstein apud Saramago).

A perspectiva para este trajeto é a Literatura Comparada, entendida sempre de uma maneira dialógica e não instrumentalizada. De forma prática e objetiva, o plano é visitar um conjunto de representações literárias que coincidam em um ponto específico: a figuração da morte. Nossa imagem primordial será o morto que fala. Nossa obra literária-guia: Memórias póstumas de Brás Cubas. A estratégia comparativista não se compõe com as ideias de influência, imitação e/ou importação de formas e de conteúdo. A comparação aqui congrega o fazer literário e a escolha de algo não consensual: o entendimento do morrer. 
Uma vez que a morte não escolhe país ou localidade, partindo deste universal, embora seguindo uma escala temporal, os livros serão trazidos e suas formas aproximadas, distanciadas, equacionadas.

Tudo começa com Memórias póstumas de Brás Cubas: um defunto autor na periferia da existência. Um morto que volta para contar a sua biografia com a pena e a tinta colhidas no sepulcro. Desta perspectiva, serão construídas as relações com a literatura do outro. Esta escolha aponta para a leitura de uma tradição a partir de um romance brasileiro do século XIX - ponto de partida, porto de chegada. O máximo denominador comum: entre mortos que falam, mortos no além, mortos que voltam, mortos que choram e gargalham, temos um defunto que é autor. Uma espécie de nada que é discurso.

Uma vez que o pensamento científico exige que este artigo seja coerente, como a vida narrada - com começo, meio, fim (e memória) -, recuperemos uma imagem da biografia redescoberta.

Pergunto: "Cada estação da vida é uma edição, que corrige a anterior, e que será corrigida também, até a edição definitiva, que o editor dá de graça aos vermes" (ASSIS, 1992, p. 549)?

Em que medida esta leitura de uma escrita da morte nos permite a consciência de que só podemos viver na história e na condição efêmera do morrer? Na perspectiva de uma tanatografia, ler é aprender a viver. A figuração da experiência no além é a aproximação de Átropos - antes que ela corte o fio discursivo. Encarar a morte literária é confrontar a ausência de mim no mundo. Meu não dizer. ${ }^{1}$

Assim, em que medida podemos entender a morte como a nossa relação com o outro, com a cultura e com o literário?

Em uma Teoria do Literário, o caminho viável é comparar obras em que o personagem e/ou personagens já estão mortos e são representados discursivamente ainda dotados de discurso.

Nesse campo, que alia linguagem e morte, pretende-se mapear uma imensa galeria de defuntos personagens, tais como aqueles presentes no Hades Homérico, no Hades Luciânico, nos Infernos de Dante e de Gil Vicente ou, ainda, os habitantes modernos de Undiscovered Countries:

\footnotetext{
1 Na única nota deste texto, atam-se as duas pontas desse mistério: recorde-se a visão de mundo na Grécia antiga, que considerava as Moiras: Láquesis, deusa dos destinos, Cloto, deusa que tecia o fio da vida, e Átropos, a responsável pelo corte. Esta última, junto com Tânatos, rompia o fio da vida. E ainda, referência também a uma espécie de tanatografia continuada no século XXI por José Saramago em As intermitências da morte.
} 
Hamlet (Fantasma), Bobók, Brás Cubas e a até mesmo a Morte-Personagem (de Saramago).

Mesmo que algumas obras extrapolem este campo de representação literária, pois não há defuntos falantes, mas há quase tantas mortes quanto personas, elas permitem ainda reflexões sobre o morrer: a ressurreição em Rabelais, o Quixote "sepultado" no segundo volume do romance de Cervantes, as meditações vieirianas sobre a Quarta-feira de Cinza, As cidades invisíveis e Palomar, de Italo Calvino, dentre outros.

Para o estudo dessas questões, conta-se ainda com o apoio teórico de Mikhail Bakhtin e de Agamben. Estes pensadores, direta e indiretamente, permitem ampliar o conhecimento sobre essa representação discursiva em uma perspectiva literária que alia o realismo e a fantasia e permitem, ainda, a aproximação dos recursos que criam uma impressão de verdade, equiparando o social e o estético como pontos de singularidade das obras.

Aproximando o movimento crítico do objeto, essa pesquisa é multifacetada. O fio que liga autores e obras é o mesmo que liga os homens - o discurso e a morte:

Nas tardes ensolaradas, a população vivente visita os mortos e decifra os próprios nomes nas lajes de pedra: da mesma forma que a cidade dos vivos esta comunica uma história de sofrimentos, irritações, ilusões, sentimentos; só que aqui tudo se tornou necessário, livre do acaso, arquivado, posto em ordem. E, para se sentir segura, a Laudômia viva precisa procura na Laudômia dos mortos a explicação de si própria não obstante o risco de encontrar explicações a mais ou a menos: explicações para mais de uma Laudômia, para cidades diferentes que poderiam ter existido mas não existiram, ou razões parciais, contraditórias, enganosas (CALVINO, 2000, p. 127-128).

Essa imagem do ser que sabe que morre e que continua discursando é a realização de um fato inusitado: a experienciação da ausência de si mesmo no mundo. A experienciação de si mesmo em outra condição que não o eu no mundo. Embora o ser dotado de discurso abrigue as prerrogativas de um Eu carnal e presentificado, há um nada que preenche nosso antes e um nada pleno que preenche o nosso depois.

Nesse sentido, uma memória do gênero literário mostra que os personagens defuntos pertencem a uma archaica longeva: a tradição cultural e literária de discursos dos mortos. No universo difuso e rabugento, o olhar ce- 
miterial retrata a existência passada e a existência no reino desconhecido do nada, fundindo realidade e fantasia. Com isso, mescla a gargalhada desfigurante e a negatividade cética com o que há de mais significativo nas mais diversas obras: viver.

Ainda no plano teorizante, Mikhail Bakhtin, com seus estudos sobre o romance, os discursos estilizados nos campos ético e estético, e a sua referência à tradição humorística, calcada na Sátira Menipeia, certamente abriu um horizonte de perspectiva para a análise histórica comparativista. Daí o entendimento de uma arquitetônica da respondibilidade que extrapola os campos da intertextualidade, da citação, da influência etc. Trata-se de entender a literatura a partir de uma imagem de uma forma de uma única especificidade e compreender como cada época trata de maneira tão diferente e tão semelhante o mesmo assunto, a mesma angústia do trespasse. Ainda nesta perspectiva, trata-se de mapear diferentes representações para o mesmo conjunto de questões suscitadas, neste caso, pela ideia de morte. Na literatura, o personagem volta para existir, enquanto recordação, na lembrança dos outros, e na memória coletiva. $\mathrm{Na}$ condição autoral e humana de quem conta uma história, todo homem deseja ser imortal, mas "sabe que morre".

De Aquiles a Brás Cubas há uma vontade de viver compartilhada, coextensiva, coexistente? Ao tratar de defuntos personagens questiona-se um eu, em novos âmbitos da linguagem, um eu biográfico e carnal, com elementos que enformam um saber literário, que permitem formular uma teoria do literário e de uma vida pelo discurso resumida no seguinte diagrama:

livro $=$ leitura $=$ sentimento $/$ ideias $=$ diálogo $=$ livros $=$ crítica literária $=$ silêncio

O diálogo é a estrutura central de qualquer existência e da existência com o outro. Nesta arquitetônica tanatográfica, a respondibilidade erige um deslocamento na relação eu-outro. Como coloca Agamben, a morte é um não-ser, é um estar-no-outro (2006).

Ou ainda, como coloca Machado em Memórias póstumas: preciso da memória do outro, preciso do discurso do outro, preciso de meu nome em uma lápide para que tudo faça sentido (1992).

Ou então, com Italo Calvino, preciso projetar uma outra existência, em um outro-lugar, para que possa suportar o mundo sem mim: 
O senhor Palomar decide que doravante procederá como se estivesse morto, para ver como o mundo se comporta sem ele. [...]

Em suma, estar morto é menos fácil do que poderia parecer. Em primeiro lugar, não se deve confundir estar morto com não existir, condição que ocupa também a interminável extensão de tempo que precede ao nascimento, aparentemente simétrica com a também ilimitada que se segue à morte. Na verdade, antes de nascer fazíamos parte das infinitas possibilidades de vida que poderiam ou não realizar-se, enquanto mortos já não podemos nos realizar nem no passado (a que pertencemos então de todo mas sobre o qual já não podemos influir) nem no futuro (que, embora influenciável por nós, nos permanece vedado). O caso do Senhor Palomar é na realidade mais simples, tendo em vista que sua capacidade de influenciar sobre algo ou alguém sempre foi considerada desprezível; o mundo pode perfeitamente passar sem ele, e ele pode considerar-se morto com toda a tranqüilidade, sem precisar sequer mudar seus hábitos. O problema é a mudança não naquilo que faz mas no que é, e mais precisamente no que é em relação ao mundo. Antes, por mundo ele entendia o mundo mais ele; agora se trata dele mais o mundo sem ele (2000, p. 108).

Este ver o mundo sem o eu é oferecido justamente na experiência literária. Você experiencia o não estar na civilização ao deparar-se com fantasmas, espíritos, seres que voltam sem explicação minimamente plausível e que constituem-se de discurso. A mesma matéria que constitui os vivos. A matéria que enforma um aqui, que torna palpável o agora, este discurso no qual vivemos todos os dias e que formamos estando juntos. Isso significa dizer que essa abordagem crítica e comparada aponta obras literárias cuja morte é temática central. Nas tanatografias há variantes: defuntos que dialogam dramaticamente no além; o encontro entre vivos e mortos; ou ainda, no caso de seres que morreram e que voltaram para contar suas experiências de mundo e/ou do além, o interesse reside na personificação daquilo que não pode ser realizado: um defunto falar.

Nessa decomposição discursiva, a biografia que, aparentemente, havia terminado com o ponto final do enterro, continua no vazio - no-nada que é escrita. No turbilhão das vozes, o leitor reconhece uma atmosfera de dúvida e de insegurança, misturada com uma profunda vontade de contar aquilo que vem depois do fim. Neste sentido, a tanatografia não é considerada aqui como o contrário da biografia. Nem mesmo no sentido de um insistente culto aos mortos depois que eles se vão - como é discutido 
em Todos os nomes, de José Saramago (2003). Embora possamos traduzir literalmente: bio-grafia, história de uma vida; tanato-grafia, história de um morto. Assim, estas duas palavras-imagens aproximam-se em uma outra: literatura.

Importa perceber que toda tanatografia é organizada no momento em que o fio é cortado. Naquilo que é dito depois do fim. Daquilo que ocorre após o último ato. Neste momento reside a consciência da volatilidade do ser (BLANCHOT, 1987), das transformações de cada época (ARIÈS, 2003), do parco tempo das ações humanas que se precipitam em um átimo de existência - metonímia de humanidade, de história, de narrativa.

Pensar essa representação da morte no novo milênio é mapear as mudanças históricas e literárias a partir dos avanços da ciência, da medicina e das relações urbanas e familiares. Como nos mostra Terry Eagleton, em Depois da Teoria, a morte é uma área da teoria cultural que passa a estar no centro das discussões:

[...] para nós, o presente é sempre parte de um projeto inacabado - o que faz nossas vidas serem como crônicas, e não narrativas. [...] Não podemos viver fora da história: ela é nosso destino, tanto quanto a morte. [...] Como Wittgenstein percebeu, a eternidade, se existe em algum lugar, há de ser aqui e agora (2003, p. 282).

Nossa vida vira uma narrativa, ou um romance, como nos ensinou Brás Cubas, quando morremos. Analisar um discurso sobre a morte é pensar sobre a solidão do fim. Sobre este conjunto de crônicas que escrevemos estando juntos no dia a dia. Juntos na solidão da escrita, na solidão da leitura, na solidão do fim. O acabamento que leva o ser humano a imaginar novas existências e que faz o ser de papel voltar para contar, a narrar para não morrer: uma forma de burlar aquilo que é interdito pelo silêncio (totalizante). Neste sentido, discute-se como o não experienciável constitui-se, ao mesmo tempo, como uma compreensão das contradições humanas (BLANCHOT, 1987).

Neste longo baile de máscaras chamado existência, a única maneira de enfrentar o trespasse, e não exatamente de vencê-lo, é o discurso. Enfim, nestas reflexões, pretende-se demonstrar como o literário é um aprendizado do morrer. Ouçamos algumas vozes que de tão longe vem vindo. Citemos alguns mestres na arte do discurso sobre a morte. Comecemos por um padre: 
Memento homo, quia pulvis es, et in pulverem reverteris [Recorda homem, vós sois pó e ao pó retornarás](Epígrafe retirada do Gênesis 3,19).

Duas cousas prega a Igreja hoje a todos os mortais: ambas grandes, ambas tristes, ambas temerosas, ambas certas. Uma é presente, outra futura: mas a futura vêem-na os olhos; a presente não a alcança o entendimento. E que duas cousas enigmáticas são estas? Pulvis es, et in pulverem reverteris (Sermão de Quarta-Feira de Cinza, 1672).

Pulvis es, et in pulverem reverteris [Sois pó, e ao pó retornarás] (Epígrafe retirada do Gênesis 3, 19).

Duas cousas prega hoje a Igreja a todos os mortais; ambas grandes, ambas tristes, ambas temerosas, ambas certas. Assim comecei eu o ano passado quando todos estávamos mais longe da morte: mas hoje que também estamos todos mais perto dela, importa mais tratar do remédio que encarecer o perigo (Sermão de Quarta-Feira de Cinza, 1673).

Mestre no ofício da Salvação, mestre no discurso epifrásico, segundo Os Evangelhos, Padre Vieira passou parte de sua existência pregando sobre uma outra existência: a vida post mortem. Mas tudo é pó e pó nesta maneira epifrásica de utilizar a biografia (evangelhos) de um Deus que encarnou, sofreu e morreu senão para salvar os homens. Se não para experienciar, na própria carne, a morte.

Ao longo de um ano, em duas longas Quartas-Feiras de Cinza, Vieira refletiu sobre o bem viver e o bom morrer. Ameaçando com a força do medo cósmico do fim, este homem na fronteira entre dois períodos (medieval e moderno), na fronteira entre dois continentes (Europa-América), na fronteira entre dois mundos (Padre e Porta-Voz), lança ao seu interlocutor um conjunto de dúvidas e conclui o primeiro dos seus sermões com perguntas, como se tivesse a certeza de que, um ano depois, poderia respondê-las: "Primeiro, quanto tenho vivido? Segundo, como vivi? Terceiro, quanto posso viver? Como é bem que viva? Torno a dizer para que vos fique na memória: Quanto tenho vivido? Como vivi? Quanto posso viver? Como é bem que viva? Memento homo?" (Sermão de Quarta-Feira de Cinza, 1672). Vieira pressupõe a resposta para as próprias perguntas. Seja nesta vida, seja na outra, não faz diferença e, no entanto, todas as manhãs de missa dava lições de partir. 
Mesmo que o homem pense mais na morte e descubra novas formas de linguagem, novas formas de representar, suas respostas estão voltadas para a vida. A própria ideia de morte é resposta para o peso da insustentável leveza da vida. Para a investigação, a transformação e a construção de sentidos, também chamados de respostas, onde encontrar sabedoria? Na volta bio/tanato-gráfica e ao se perguntar como se deu o tempo de minha vida, os meus modos de morrer e os dos outros, o desejo de mais viver e como sobreviver à morte senão pelo discurso. Desta representação literária extrai-se uma sabedoria.

Machado de Assis imortalizou-se na criação de um defunto autor. Brás Cubas, um indivíduo, um personagem escritor que evoca justamente a maneira de contar a própria vida no instante dos acontecimentos. Uma vida cheia de intermitências, percebidas apenas nas memórias - póstumas. Sigamos a pista deste guia. Todo guia é terrível:

Trata-se, na verdade, de uma obra difusa, na qual eu, Brás Cubas, se adotei a forma livre de um Sterne ou de um Xavier de Maistre, não sei se lhe meti algumas rabugens de pessimismo. Pode ser. Obra de finado. [...] Conseguintemente, evito contar o processo extraordinário que empreguei na composição destas Memórias, trabalhadas cá no outro mundo (ASSIS, 1992, v. 1, p. 513).

De forma muito sucinta, realizando uma "prática histórica", no sentido empregado por Ariès, é necessário apontar o percurso do tema ao longo dos séculos. Passemos a classificá-las e, em seguida, estabeleçamos uma concepção de conjunto de uma perspectiva comparativista dialógica com Memórias póstumas de Brás Cubas. Nos primeiros tempos, sempre, ao menos um defunto-personagem:

1) No Hades Homérico: Odisseu, vivo, conversa com espectros e seres religiosos (mitológicos) - Canto XI. Chama a atenção o astucioso Odisseu, aquele que nunca morre nas representações de Homero, conversando com alguns defuntos. Nesta catábasis tem-se (com fingimento ou não) parte de sua biografia. Amigos guerreiros, mulheres emblemáticas, sua mãe, algumas figuras de narrativas orais gregas. Do ponto de vista de cada um deles, o personagem tem uma ideia da morte, do morrer e das lembranças e lamentos sobre a vida passada e deixada por uma existência no longínquo vale do esquecimento. Não há riso, 
não há coragem, apenas lamentações. Mas o personagem que gostava de experienciar, de desafiar, foge da morte, como Heitor fugira de Aquiles. Um herói épico que teme e foge da Medusa.

2) No Hades Luciânico: mortos conversam com mortos e com seres religiosos (mitológicos). Retomando parodicamente o Hades Homérico, os personagens cínicos, que passaram a vida se preparando para o morrer, gargalham daqueles que, como o Aquiles da Odisseia, lamentam a perda e têm apego por tudo que foram e viveram. Nestes diálogos de origem socrática, alguns mortos aceitam a descida e deleitam-se por esta autonomia. Ao passo que outros, tipificados e/ou emblemáticos, choram o triste fim. Na Sátira Menipeia de Luciano de Samósata, a paródia, o cinismo, a discussão do presente são predominantes. Chama a atenção um detalhe: Odisseu é defunto em um dos diálogos (LUCIANO, 2007).

3) Na Commedia de Dante: um escritor-personificado e cristão é guiado por um defunto e não cristão, Virgílio. Conversa com mortos classificados cristamente no Inferno, Limbo, Purgatório, Paraíso. Uma galeria de defuntos é visitada e minuciosamente descrita para que os fiéis temam o Inferno - o mais belo dos cenários. Os três volumes do escritor florentino nada mais são que um conjunto de defuntos catolicamente organizados nos três (quatro) mundos possíveis de se habitar depois do trespasse: Paraíso, Inferno, Purgatório (e Limbo). Na mesma tradição, retoma os diálogos dos mortos de Luciano, os Evangelhos de um Deus que nasce, sofre e morre e a catábasis homérica - por sua vez, já reinventada na pena de Virgílio, autor de Eneida (século I) e transformado em personagem de Dante (século XIV).

4) Nos Autos das Barcas de Gil Vicente: diálogo dos mortos com mortos e presença de seres religiosos (mitologia cristã). Uma trilogia teatral dos mortos cristãos é composta nos seus Autos: da Barca do Inferno (1517), do Purgatório (1518) e da Glória (1519). Uma galeria divertida de pobres e nobres, pecadores e beatificados, bobos e sábios disputando um lugar nas (três) galeras que levam para os habitáculos das almas. Os perdoados são sempiternamente salvos, os julgados são contundentemente condenados a uma existência de dor e de horror. E os pobres, pecadores, condenados a purgar... 
5) No Hamlet de Shakespeare: um fantasma desencadeia a trama e o drama. Aparição e diálogo entre um morto e um vivo (seu porta-voz e agente). Do Undiscovered Country, o Fantasma Hamlet retorna. Ex-Rei, Ex-Pai, Ex-Marido, impulsiona uma sequência de mortes - ocasionadas pelo seu inventivo filho de mesmo nome. Como se convidasse a todos a compartilharem de sua condição, o espectro volta para pedir vingança. Pede ao filho titubeante que tire a vida de quem teria tirado a sua. Isto acontece, mas não sem que, antes, outros também tenham suas vidas abaladas e retiradas dramaticamente. Apenas Horácio sobrevive para contar.

Pensando em gêneros literários, deixamos um conjunto clássico de epopeias, diálogos socráticos parodiados, uma Commedia, autos e dramas.

$\mathrm{Na}$ modernidade, passamos para as tanatografias da prosa: um estudo do diálogo dos mortos na perspectiva dialógica do gênero da modernidade - o romance.

Mesmo que algumas obras extrapolem o campo de representação literária que contém defuntos personagens, pois, no sentido mais restrito, em Rabelais, Cervantes e Padre Vieira não há defuntos falantes, mas há quase tanta morte quanto personas, elas se integram às outras, cuja representação traz defuntos e permite reflexões sobre o morrer na modernidade:

6) A ressurreição em Rabelais: representação do Inferno cristão de uma perspectiva saturnal (romana-pagã). Vivo que morreu e voltou para contar. A análise deste episódio permite atualizar os discursos dos mortos anteriores e aponta elementos para um estudo da Literatura e Morte na Modernidade (SILVA JR., 2008).

7) Quixote "sepultado" no segundo volume do romance de Cervantes: de quando um personagem é brutalmente assassinado pelo autor de carne e osso, visando, assim, evitar versões apócrifas. Estudo dos Prólogos de uma perspectiva dialógica e tanatográfica. Bases para pensar Morte e Modernidade.

8) Meditações vieirianas sobre a Quarta-Feira de Cinza: sermões sobre o período da quaresma e reflexões sobre morte e cristianismo. Basicamente, ao longo dos mais de duzentos sermões que o Padre deixou, 
boa parte deles integra, em algum momento, esta perspectiva de um fim ameaçador para quem não agir no mundo fazendo prevalecer sua ação positiva, ao lado de Cristo, no outro mundo.

9) “Bobók" - diálogo dos mortos de Dostoiévski: no século XIX o escritor russo integra-se à longa tradição da Sátira Menipeia. Nesta perspectiva reside a revolução do romance ocidental e a revolução da crítica literária com o método polifônico de Dostoiévski e apreendido por Mikhail Bakhtin.

10) Memórias póstumas de Brás Cubas: pela primeira vez na história da Literatura um defunto assume, com tanta autonomia, a própria autoria de um romance. Extrapolando, repetindo e superando a longa tradição de discursos dos mortos, a representação tanatográfica machadiana é o desfecho e o pilar deste método polifônico de análise comparada. Com ele também podemos fazer um panorama da literatura e da morte na modernidade e apontar análises de obra nos séculos XX e XXI.

Enfim, a partir deste percurso e do defunto autor de Memórias póstumas de Brás Cubas, algumas perguntas sobre a tanatografia podem ser lançadas: Um personagem morre? Na nossa memória há uma diferença entre recordar uma pessoa viva e uma pessoa morta? O mesmo se dá com um personagem? Então, na nossa memória pessoas e personagens são a mesma coisa? Posso amar mais um personagem do que um ser de carne e osso? O mundo é imenso ou apenas o que vejo de minha janela? Envelhecer é colecionar mortos? É verdade que o melhor lugar para ler e escrever é o cemitério?

Sem uma resposta definitiva, última citação de Italo Calvino:

Pensando na própria morte, Palomar pensa já naquela dos últimos sobreviventes da espécie humana ou de seus descendentes ou herdeiros: no globo terrestre devastado e deserto desembarcam exploradores de um outro planeta, decifram os traços registrados nos hieróglifos das pirâmides ou nas fichas perfuradas das calculadoras eletrônicas; a memória do gênero humano renasce de suas cinzas e se dissemina pelas zonas habitadas do universo. E assim de procrastinação em procrastinação se chega ao momento em que será o tempo de se consumir e se 
extinguir num céu vazio, quando o último suporte material da memória de viver se houver degradado numa chama de calor, ou tiver cristalizado seus átomos no gelo de uma ordem imóvel.

"Se o tempo deve acabar, pode-se descrevê-lo, instante por instante", pensa Palomar, "e cada instante, para se poder descrevê-lo se dilata tanto que já não se vê mais seu fim". Decide que se porá a descrever cada instante de sua vida, e enquanto não os houver descrito a todos não pensará mais em estar morto. Neste momento morre (1994, p. 112).

A própria condição sepulcral já é resposta à longa archaica. Ora repudiando, ora se aproximando, renova a intimidade e uma repulsa fingida e paradoxal, demonstrando o desejo de viver. A vontade de ser lido (coisa de vivo) e o desprezo aparente (coisa de morto) promovem a tentativa de dobrar o público à "tirania" burlesca e desafiadora da tanatografia. Por isso, em Memórias póstumas de Brás Cubas há traços das discussões literárias travadas há séculos. Esta genealogia do defunto confronta a questão da literatura nacional e funda uma representação literária oblíqua. Uma tanatografia que alia discurso e morte em uma tradição tão antiga quanto viver: a tradição do morrer e do contar.

\section{Referências Bibliográficas}

AGAMBEN, Giorgio. A linguagem e a morte: um seminário sobre o lugar da negatividade. Trad. Henrique Burigo. Belo Horizonte: Editora UFMG, 2006.

ALIGHIERI, Dante. A Divina Comédia. Trad. I. E. Mauro. São Paulo: Editora 34,1998 . v. 3.

ARIĖS, Philippe. História da morte no Ocidente. Trad. Priscila Viana de Siqueira. Rio de Janeiro: Ediouro, 2003.

ASSIS, Machado. Memórias póstumas de Brás Cubas. In: Obra completa. Afrânio Coutinho (Org.). Rio de Janeiro: Nova Aguilar, 1992. v. 3.

BAKHTIN, Mikhail. A cultura popular na Idade Média e no Renascimento: o contexto de François Rabelais. São Paulo: Annablume/Hucitec, 2002. . Problemas da poética de Dostoiévski. Rio de Janeiro: Forense Universitária, 2002. 
Questões de literatura e de estética: a teoria do romance. São Paulo: Annablume/Hucitec, 2002.

BLANCHOT, Maurice. O espaço literário. Rio de Janeiro: Rocco, 1987.

CALVINO, Italo. As cidades invisíveis. São Paulo: Companhia das Letras, 2000. . Palomar. Trad. Ivo Barroso. São Paulo: Companhia das letras, 1994.

CERVANTES, Miguel de. O engenhoso fidalgo Dom Quixote de la Mancha. Trad. Eugênio Amado. Belo Horizonte: Itatiaia, 1997. v. 2.

DOSTOIÉVSKI, Fiódor. Dostoiévski: "Bobók”. Trad. Paulo Bezerra. São Paulo: Editora 34, 2005.

EAGLETON, Terry. A morte, o mal e o não-ser. In: . Depois da Teoria. Rio de Janeiro: Civilização Brasileira, 2003.

FROIDMONT, Hélinand. Os versos da morte. São Paulo: Ateliê Editorial, 1996.

HOMERO. A Ilíada. Trad. Haroldo de Campos. São Paulo: Mandarim, 2001. . Odisséia. Trad. D. Schüler. Porto Alegre: L\&PM, 2007. v. 3.

LUCIANO. Diálogo dos mortos. Trad. H. G. Muracho. São Paulo: Palas Athena, 1996.

MONTAIGNE, Michel. Ensaios. Brasília: Editora Universidade de Brasília, 1987.

RABELAIS, François. Gargântua e Pantagruel. Trad. David Jardim Júnior. Belo Horizonte; Rio de Janeiro: Villa Rica, 1991. v. 2.

SARAMAGO, José. Todos os nomes. São Paulo: Planeta, 2003. . As intermitências da morte. São Paulo: Companhia das Letras, 2005. SHAKESPEARE, William. Hamlet. Trad. Sophia de Mello Breyner Andresen. Porto: Lello \& Irmão Editores, 1987.

SILVA JR., Augusto. R. Morte e decomposição biográfica em Memórias Póstumas de Brás Cubas. 2008. 216 f. Tese (Doutorado) - Instituto de Letras, Universidade Federal Fluminense, Niterói, 2008. Disponível em: <http:// www.bdtd.ndc.uff.br/tde_busca/arquivo.php? codArquivo=2500>. Acesso em: 15 mar. 2010. 
VICENTE, Gil. Auto da Barca do Inferno. Rio de Janeiro: Grifo Edições, 1971.

VIEIRA, Padre António. Sermões de Quarta-Feira de Cinza. In: . Sermões. Porto: Lello \& Irmão - Editores, 1959. I v., II tomo, p. 167-277. 